\title{
Fathers - An Untapped Resource for Increasing Physical Activity among African American Girls
}

\author{
Tara B. Blackshear ${ }^{1}$
}

Affiliations: 'Towson University, Department of Kinesiology, Towson, MD, USA

Correspondence: T. B. Blackshear, Towson University, Department of Kinesiology, 8000 York Rd, Towson, MD 21204, USA.E-mail: tblackshear@towson.edu

ABSTRACT African American girls' physical activity significantly declines during adolescence. Single mothers are raising many African American girls. Research on the benefits of fathers' involvement on physical activity is minimal, especially regarding girls. The current study examines the impact that fathers' involvement and family structure have on physical activity behaviours among African American adolescent girls $(n=40)$. Data were collected via a demographic questionnaire, a father involvement scale, and a leisure time exercise instrument. Data were analysed via descriptive statistics, analysis of variance, and multiple regression. African American girls' physical activity habits are positively associated with involved fathers. Girls reporting high father involvement had higher rates of physical activity than girls reporting low father involvement did. Girls from two-parent families had higher physical activity rates than girls in single-parent households, but these findings were non-significant. Fathers being actively engaged in physical activities was a significant predictor of physical activity among the study population. Fathers demonstrating nurturing and participatory behaviours, irrespective of residential or biological status, may be instrumental in promoting physical activity among African American adolescent girls. Physical activity programming targeting African American girls should include fathers and other male figures, as they may be instrumental in keeping African American girls physically active.

KEY WORDS parental involvement, exercise, African American families, health promotion

$@$ MJSSMontenegro

FATHERS \& PHYSICAL ACTIVITY

http://mjssm.me/?sekcija=article\&artid=169

\section{Introduction}

Physical activity (PA) levels have been shown to sharply decline during adolescence, and this trend continues over the lifespan (Center for Disease Control and Prevention [CDC], 2012). The benefits of PA are widely known and include risk reduction for heart disease, diabetes, obesity, some cancers, weight management, stress relief, and mood enhancement (U.S. Department of Health and Human Services [USDHHS], 2008). Physical activity has also been shown to improve the overall quality of life and increase life expectancy (Jia \& Lubetkin, 2014). Despite this, many youths fail to meet PA recommendations, especially African American females (USDHHS, 2008; American Heart Association [AHA], 2013). For instance, the American Heart Association (2013) reported African American adolescent girls to have the highest prevalence (26.7\%) of inactivity compared to Latina (21.3\%) and Caucasian (13.7\%) girls. Furthermore, research exploring PA promotion amongst African American girls relied heavily on mothers' influence and excluded fathers (Ransdell et al., 2004). Given that African American women are one of the least active groups, the reliance solely on mothers may not be as influential as relying on fathers.

\section{Resident vs Non-resident Fathers}

Resident fathers live with their children while non-resident fathers live in a different household than their children. The benefits of having a resident father include lower behaviour risks, better health, greater financial stability, and greater opportunities to be involved in youth activities (Bramlett \& Blumberg, 2007). In addition, children living with their fathers tend to have higher self-esteem, lower rates of obesity, and are 
more likely to model their father's PA habits (Trost, Kerr, \& Ward, 2001). Alternatively, studies investigating non-resident fathers often highlight the disadvantages rather than potential benefits (Lucas, Nicholson, \& Erbas, 2013). Favourable outcomes, however, are evident when non-resident fathers are involved, and their relationship with the other parent is healthy. For example, African American non-resident fathers have been shown to provide more caregiving to children than Caucasian counterparts (Fagan \& Palkovitz, 2007; Leavell, Tamis-LeMonda, \& Ruble, 2012). Given this, there is evidence to suggest that African American fathers are more involved than previous research has demonstrated.

\section{Fathers' Involvement}

The benefits of fathers' involvement in various domains of health and well-being are abundant (AlleyneGreen, et al., 2015; Ali \& Dean, 2015; Coley, 2003), but research exploring benefits of fathers' involvement on PA practices among their daughters is negligible. Especially research with African American girls. Despite limited research, African American girls have reported that biological fathers positively influence their PA practices (Taylor et al., 1999). Moreover, as African American females struggle to maintain adequate amounts of PA (USDHHS, 2008), fathers may be a catalyst for increasing PA among them.

Fathers' involvement has been shown to be beneficial in other areas of health, including reducing the risk of sexual behaviours, dating violence (Alleyne-Green, et al., 2015), smoking cigarettes (Ali \& Dean, 2015) and depression (Coley, 2003). Problematically, these studies only included residential fathers, which puts African American girls at a disadvantage because they are more likely to have non-resident fathers (Pew Research, 2015). Furthermore, father involvement studies commonly use quantifiable characteristics, such as time spent with children (Waller \& Swisher, 2006) and financial support (Cooksey \& Craig, 1998). Unfortunately, these categories, again, disadvantage African American fathers because a higher proportion of them do not reside with their children and many suffer from a lower socio-economic status (Waller \& Swisher, 2006). Given this, not only is research on fathers' involvement negligible, but it also fails to take into account the cultural complexities of many African American families.

\section{Fathers' Involvement and Physical Activity}

Research has shown that fathers' involvement has a beneficial impact on boys' PA behaviours (Leavell et al., 2012; Zahra, Sebire, \& Jago, 2015). The role fathers play in their sons' PA pursuits including "physical play" (Leavell et al., 2012) and higher rates of sports participation (Ellis, Caldwell, Assari, et al., 2014). Father impact may, therefore, be instrumental in boys' rates of PA as well as a slower decline of PA over their lifespan (USDHHS, 2008). Recognizing that fathers promote PA with their sons, one could argue that increased and sustained PA levels might result with daughters as well. This type of contribution is possible regardless of residence status, so PA studies exploring African American girls should consider the role of fathers. This study addresses this gap in the literature by using an inclusive approach to investigate the impact of father involvement on African American adolescent girls' PA behaviours.

It comes as no surprise that there is a positive relationship between fathers' and adolescent PA levels (Sukys et al., 2014). More specifically, the PA rates of sons and daughters directly correlated to the rates of PA of fathers (Sukys et al., 2014). Also, fathers had higher rates of PA than mothers did, and when a father had a high rate of PA, the children also had higher rates of PA (Sukys et al., 2014). This parent-child outcome was not evident in mother-child relationships (Sukys et al., 2014), posing additional challenges for African American girls. Additionally, these findings are consistent with non-African American families (Zahra, Sebire, \& Jago, 2015), increasing concerns for African American girls as they are more likely to be inactive than girls of other ethnic groups (CDC, 2012; Kimm et al., 2002; USDHHS, 2008; AHA, 2013).

Fortunately, studies have shown that fathers positively influence daughters' PA behaviours. The limited studies available, however, tend to focus on children under the age of 10. For example, Krahnstoever et al.s (2003) study of nine-year-old girls reported that parental influence, including fathers, increased girls' PA levels. Fathers also positively influenced pre-school aged children in vigorous PA (Vollmer et al., 2015). Furthermore, it has been found that "father-child time" and playing sports together also increased kindergartners' PA levels (Beets \& Foley, 2008). These findings suggest that daughters may benefit from having an involved father in order to increase and sustain PA habits.

The prevalence of single-parent, female-led households for African American families (Pew Research, 2015) contributes to stereotypes that African American fathers are not involved. While there is research exploring the links between fathers' involvement and health more broadly, there is limited research on PA specifically, especially among African American families. More pointedly, to date, there has not been a single study exploring the intersection of fathers' involvement and girls PA amongst African American families. The current study aimed to determine if and how father involvement impacts PA levels among African American adolescent girls. It was hypothesized that: 1) girls reporting high levels of fathers' involvement would have higher levels of PA than girls reporting low levels of fathers' involvement, and 2) girls living with their fathers would have higher levels of PA than girls who did not reside with their fathers. 


\section{Methods}

Participants and Setting

Forty (40) self-identified African American adolescent girls aged 13 to $18(\mathrm{M}=16.18, \mathrm{SD}=1.17)$ attending a public magnet high school in North Carolina (USA) completed surveys. The school was $66 \%$ African American, located in a predominately African American neighbourhood but attracted diverse students from around the county.

\section{Procedures}

On-site information sessions, flyers posted around the school and in-class promotion aided in recruitment. After initial contact, participants received study details, assent and parental consent packets. Arrangements made via email or phone call confirmed the location, time and date to return the required documents. Participants received reminder phone calls the evening before their appointments. Data collection occurred at the school or public locations near the participants' homes. Questionnaires took 15-20 minutes to complete, and participants received a $\$ 5$ gift card to a local eatery, and free gym passes to a local fitness centre.

\section{Variables and Measures}

Fathers' involvement. Father involvement constructs were assessed using Finley and Schwartz's Father Involvement Scale (FIS) (2004), which assesses long-term retrospective accounts of father involvement designed for adolescents and young adults. Participants were asked to identify their father figure and respond to "How involved was your father (father figure) in the following aspects of your life and development? Please place the appropriate number on the line before each of the following items (domains)". The FIS includes twenty domains and three subscales (expressive, instrumental, and mentoring/advising) on fathers' involvement in children's lives using factor analysis from previous FIS research (Finley and Schwartz, 2004). Each domain has a 1 to 5 -point value (e.g., $1=$ never involved and $5=$ always involved). Sum scores range from 20-100 and mean scores range from 1-5. The current study conducted an internal consistency reliability analysis using Cronbach's alpha yielding similar high scores to Finley and Schwartz (2004). A Physical Activities domain was added to the FIS, which used the 1 through 5 rating scale but was analysed independently. These questions explored how fathers influenced girls' PA practices.

Physical activity. PA was measured with the Godin Leisure-Time Exercise Questionnaire (GLTEQ) (Godin and Shephard, 1985). The GLTEQ assessed PA behaviours over a seven-day period and asked participants to report amounts of strenuous, moderate, and mild PA of 15 minutes or longer. An assigned metabolic equivalent value (MET) accompanied each intensity category (9, 5, and 3 respectively). Activity scores were based on total units reported under strenuous and moderate activities. Twenty-four units or more is considered active, 14-23 units are moderately active, and less than 14 units is sedentary or insufficiently active (Godin, 2011). The GLTEQ also includes the question "During a typical 7-Day period (a week), in your leisure time, how often do you engage in any regular activity long enough to work up a sweat (heart beats rapidly)?" The responses are often, sometimes, and never/rarely. Among adolescents, the GLTEQ has been shown to be reliable (Sallis et al., 1993).

Demographics. A self-created demographic questionnaire surveyed factors including age, grade, race/ethnicity, father/father-figure and family structure. In addition, if a stressful event occurred in the youth's life (e.g., divorce, death, incarceration), the survey asked at what age this occurred.

\section{Data Analysis}

The Statistical Package for the Social Sciences 15.0 (SPSS) was used for analyses. Descriptive statistics were calculated for demographic variables using a one-way analysis of variance (ANOVA) to determine group differences in the PA participation of girls who reported high versus low levels of fathers' involvement. Multiple regression analyses determined the classifications of fathers' involvement that best predicted PA.

\section{Results}

Descriptive Statistics

Forty African American girls aged 13-18 (M=16.18, SD=1.17) completed questionnaires. Twenty-four girls acknowledged biological fathers as their father figure; one acknowledged an adoptive father whom she considered biological, four identified a stepfather, five an uncle, and three a grandfather. One girl indicated that church brothers acted as father figures, one did not have a father figure and indicated that she was adopted by a single mother, and one was unable to identify a father figure. Of the 40 responses, one girl also had a father who was deceased but was active in her life prior to death. Twenty-two girls lived in single-parent households. All but one single-parent family was led by a female (20 - mother; 1- grandmother; 1 - father), and 19 girls had a resident father (16 - biological fathers; 3 - stepfathers).

Physical activity. PA scores reported on the GLTEQ ranged from 0 to 83 METS with a mean score of 39.87 METS in a 7-day period, which is generally low. Fourteen (30\%) participants were considered active with 24 units or more in the moderate to the strenuous category, nine (22.5\%) were moderately active with 14-23 units of PA, and the majority were insufficiently active $(42.5 \%)$ or in the sedentary category, with two reporting no PA. 


\section{Fathers' Involvement and Physical Activity}

After combining the Sometimes (3), Often (4) and Always (5) involved father groups into the high level of father involvement category and combining the Never (0) and Rarely (1) involved father groups into the low level of father involvement category in the $P A$ domain, girls reporting high levels of father involvement had higher levels of PA $(\mathrm{M}=44.39, \mathrm{SD}=16.48, \mathrm{p}=.055)$ than girls reporting low levels of father involvement $(\mathrm{M}=30.49, \mathrm{SD}=22.5, \mathrm{~d}=.70)$. Additionally, girls reporting higher levels of overall father involvement $(\mathrm{M}=41.69$, $\mathrm{SD}=23.91)$ had higher levels of PA than girls reporting low levels of overall father involvement $(\mathrm{M}=37.86$, $\mathrm{SD}=19.08, \mathrm{p}=.58$ ). Both results, however, were not statistically significant. The $P A$ domain had a moderately positive relationship $(\mathrm{r}=.37, \mathrm{p}=.02)$; however, the regression coefficient was not statistically significant. Further, the expressive domain on the FIS, which includes "leisure, fun, play and physical development," had a correlation of $\mathrm{r}=.34, \mathrm{p}=.03$ for $\mathrm{PA}$, and the mentoring and instrumental domains had the weakest correlations at $\mathrm{r}=.25, \mathrm{p}=.12$ and $\mathrm{r}=.20, \mathrm{p}=.22$, respectively. Last, girls with resident fathers also reported higher levels of PA ( $M=48.21, \mathrm{SD}=27.38)$ than girls with non-resident fathers $\operatorname{did}(\mathrm{M}=40.24, \mathrm{SD}=22.11, \mathrm{p}=.31)$ but the results were not statistically significant.

Responses to questions asking participants how their father/father figure influenced their PA habits complemented the quantitative findings. Twenty girls responded that their father or father figure was not instrumental in their physical activities, and twenty girls indicated that their father/father figure was instrumental in their physical activities. The responses also revealed that men other than biological fathers fulfil surrogate roles in promoting PA. Girls identified male figures including stepfathers, grandfathers, and uncles $(\mathrm{N}=14)$ as instrumental in their physical activities. Nine of 14 girls reported high levels of PA involvement from men other than their biological fathers.

\section{Discussion}

This study examined differences and associations between fathers' involvement and PA behaviours among African American adolescent girls. As fathers' involvement increased, levels of PA slightly increased. A similar pattern has been shown among Lithuanian adolescents (Sukys, 2014), for whom the PA levels of daughters and sons were higher when their fathers' physical activities were higher. This relationship was not evident with mothers, further supporting the need to investigate fathers' involvement and PA patterns. Additionally, the lack of research on fathers' impact and PA among adolescent girls of all ethnic groups is troublesome, since PA levels among females decline rapidly during adolescence (Kimm et al., 2002; USDHHS, 2008).

While there were relatively low rates of PA among the study sample, which is reflective of American society in general (CDC, 2012), this study suggests that fathers' involvement may improve PA of African American adolescent girls. Girls reporting high levels of fathers' involvement had higher rates of PA than girls reporting low levels of fathers' involvement, which warrants further inquiry. Studies have shown involved fathers are beneficial to the self-esteem and academic outcomes of African American girls (Cooper, 2009) and reduce the risk of getting pregnant (Peterson, 2007). Given this, a logical inference is that fathers' increased involvement may also increase PA outcomes among African American adolescent girls.

Nine of the 14 participants who identified a non-biological father-figure were among the higher PA group; therefore, biological fathers should not be the only men considered in PA interventions targeting African American adolescent girls. Studies have shown that non-biological African American fathers can be beneficial for African American families (Coley, 2003; McDougal, Durnell, \& Dlamini, 2018). Coley (2003) referred to these non-biological fathers as "social fathers" and recognized the cultural complexities of many African American households by including them. She found that African American girls had more trust and lower anger towards social residential fathers than to non-residential fathers and biological fathers. This perhaps illustrates the importance of relationship quality and that non-biologically related men can contribute to the upbringing of children. Perhaps the best approach to foster PA among African American adolescent girls is to embrace the African proverb, "It Takes a Village," to include and encourage other men in the community to participate as surrogate fathers to girls and families in need.

Given the above results, there are two future areas that could be explored further: (1) relating fathers PA levels: Although the current study did not assess the PA levels of fathers, can we link fathers PA levels to girls PA levels?, and (2) Are there specific ways in which fathers are involved that are linked to girls PA levels? Lastly, from a public health standpoint, mothers should be informed of the benefits of fathers' involvement on children since they are often instrumental in fostering fathers' involvement (Fagan \& Palkovitz, 2007).

\section{Limitations}

Despite the value of investigating fathers' involvement and PA among African American adolescent girls, this study's limitations included a small sample size that limits inferences and generalizations. Additionally, recall accounts used to measure PA can cause participants to over- or underreport. Furthermore, there was no objective measure (e.g., accelerometer, pedometer, heart rate monitor) of PA, and the overall activity among participants was low. Although reliable, the GLTEQ's subjectivity is a limitation inherent in recall instruments because it relies on participants' abilities to recall activity over a seven-day period; however, the reliability of the measure provided indicators (e.g., intensity and frequency of activity) to allow inferences to be made. 
The exclusion of socio-economic status and parental education was a limitation, since children from educated and affluent families tend to have higher PA levels than those from economically disadvantaged homes (CDC, 2012; Drenowatz et al., 2010). Further, parents were not asked to participate because children are often the best assessors of their fathers' involvement (Day \& Lamb, 2004; Finley \& Schwartz, 2004). Finally, the study excluded mothers; however, the focus on fathers was justified due to their absence in current interventions and conversations regarding daughters' PA.

\section{Conclusion}

This study identified father figure behaviours that may be instrumental in promoting the PA of African American girls. Previous studies have shown that these behaviours have been effective with sons (Zahra, Sebire, \& Jago, 2015). Fathers may promote the physical activities of their daughters, similarly to sons, by increasing expectations that they be physically active, which may result in sustained PA over their lifespans. The findings of this study address a gap in the literature and act as a catalyst for further inquiry and discussion that includes the role of fathers, regardless of their biological relationship and residential status, in promoting PA among African American adolescent girls. Future research in PA that focuses on African American girls should consider the entire family dynamics, which should include the father.

\section{REFERENCES}

Alleyne-Green, B., Grinnell-Davis, C., Clark, T. T., \& Cryer-Coupet, Q. R. (2015). The role of fathers in reducing dating violence victimization and sexual risk behaviors among a national sample of Black adolescents. Children and Youth Services Review, 55, 48-55. doi:10.1016/j.childyouth.2015.04.005

American Heart Association. Statistical Fact Sheet 2013 Update. (2013). Physical Inactivity Retrieved from https://www.heart.org/idc/groups/heartpublic/@wcm/@sop/@smd/documents/downloadable/ ucm_319589.pdf

Barr-Anderson, D.J., Adams-Wynn, A.W., Alhassan, S., et al. (2014). Culturally-appropriate, family- and community- based physical activity and healthy eating intervention for African-American middle schoolaged girls: A feasibility pilot. Journal of Adolescent and Family Health 6(2): Article 6.

Beets, M. W., \& Foley, J. T. (2008). Association of Father Involvement and Neighborhood Quality with Kindergartners' Physical Activity: A Multilevel Structural Equation Model. American Journal of Health Promotion, 22(3), 195-203.

Bramlett, M.D., \& Blumber, S.J. (2007). Family structure and children's physical and mental health. Health Affair, 26(2): 549-558.

Centers for Disease Control and Prevention (2012). Division of nutrition, physical activity, and obesity. Retrieved from www.cdc.gov/nccdphp/dnpao/index.html (accessed date is unknown).

Coley, R. L. (2003). Daughter-father relationships and adolescent psychosocial functioning in low-income African American families. Journal of Marriage and Family, 65, 867-875.

Cooksey, E.C., \& Craig, P.H. (1998). Parenting from a distance: The effects of paternal characteristics on contact between nonresidential fathers and their children. Demography 35(2): 187-200.

Cooper, S.M. (2009). Associations between father-daughter relationship quality and the academic engagement of African American adolescent girls: Self-esteem as a mediator? Journal of Black Psychology, 35(4): 495-516.

Day, R., \& Lamb, M. (2004). Conceptualizing and Measuring Father Involvement. Mahwah, NJ: Routledge.

Davison, K. K., Cutting, T. M., \& Birch, L. L. (2003). Parents' activity-related parenting practices predict girls' physical activity. Medicine \& Science in Sports \& Exercise, 35(9), 1589-1595. doi:10.1249/01. MSS.0000084524.19408.0C

Drenowatz, C., Eisenmann, J.C., Pfeiffer, K.A., et al. (2010). Influence of socio-economic status on habitual physical activity and sedentary behavior in 8- to 11-year old children. BMC Public Health, 10, 214.

Ellis, K.R., Caldwell, C.H., Assari, S., et al. (2014). Nonresident African American fathers' influence on sons' exercise intentions in the fathers and sons program. The Science of Lifestyle Change, 29(2): 89-98.

Fagan, J., \& Palkovitz, R. (2007). Unmarried, nonresident fathers' involvement with their infants: A risk and resilience perspective. Journal of Family Psychology, 21(3): 479-489.

Finley, G.E., \& Schwartz, S.J. (2004). The father involvement and nurturant fathering scales: Retrospective measures for adolescent and adult children. Educational and Psychological Measurement, 64(1): 143-164.

Godin, G., \& Shephard, R.J. (1985). A simple method to assess exercise behavior in the community. Canadian Journal of Applied Sport Sciences, 10, 141-146.

Jia, H., \& Lubetikin, E.I. (2014). Comparing quality-adjusted life expectancy at different levels of physical activity. Journal of Physical Activity and Health, 11, 278-284.

Kimm, S., Glynn, N., Kriska, A., et al. (2002). Decline in physical activity in African American girls and white girls during adolescence. The New England Journal of Medicine, 347(10): 709-715.

Leavell, A., Tamis-LeMonda, C., Ruble, D., Zosuls, K., \& Cabrera, N. (2012). African American, White and Latino Fathers' Activities with their Sons and Daughters in Early Childhood. Sex Roles, 66(1-2), 53-65. doi:10.1007/s11199-011-0080-8

Lucas, N., Nicholson, J.M., \& Erbas, B. (2013). Child mental health after parental separation: The impact of 
resident/non-resident parenting, parent mental health, conflict and socioeconomics. Journal of Family Studies, 19(1): 53-69.

McDougal, I. I. I. S., Durnell, E., \& Dlamini, P. Z. (2018). Social father presence: The experience of being raised by Black social fathers. Journal of Pan African Studies, 11(6), 1-23.

Peterson, S.H. (2007). The importance of fathers: Contextualizing sexual risk-taking in "low-risk" African American adolescent girls. Journal of Human Behavior in the Social Environment, 15, (2/3), 329-346.

Pew Research Center (2015). Parenting in America: Outlook, worries, aspirations are strongly linked to financial situation. Available at: www.pewsocialtrends.org/2015/12/17/1-the-american-family-today/ Retrieved July 17, 2017.

Ransdell, L.B., Delting, N.J., Taylor, A., \& Reel, J., Barry, S. (2004). Effects of home- and university based programs on physical self-perception in mothers and daughters. Women and Health, 39(2): 63-81.

Raudsepp, L, \& Viira, R. (2000). Influence of parents' and siblings' physical activity on activity levels of adolescents. European Journal of Physical Education, 5, 169-178.

Sallis, J. F., Haskell, W. L., \& Wood, P. D., Fortmann, S. P., Rogers, T., Blair, S. N, \& Paffenbarger, R. (1985). Physical activity assessment methodology in the Five-City Project. American Journal of Epidemiology, 121(1), 91-106.

Sukys, S., Majauskiene, D., Cesnaitiene, V.J., et al. (2014). Do parents' exercise habits predict 13-18-year-old adolescents' involvement in sport? Journal of Sports Science and Medicine, 13, 522-528.

United States Department of Health and Human Services/Center for Disease Control and Prevention. (2008). Physical Activity Guidelines for America, Retrieved from https:/health.gov/paguidelines/guidelines/

Waller, M.R., \& Swisher, R. (2006). Fathers' risk factors in fragile families: Implications for "healthy" relationships and father involvement. Social Problems, 53(3): 392-420.

Zahra, J., Sebire, S.J., \& Jago, R. (2015). "He's probably more Mr. Sport than me": A qualitative exploration of mothers' perceptions of fathers' role in their children's physical activity. BMC Pediatrics 15(1): 1-9. 